\title{
A Study on Effect of Club Activity for Elderly with Dementia on College Life Satisfaction, Dementia Knowledge, and Dementia Attitude
}

\author{
Young-Sun Park ${ }^{1}$ and Young-Ju Jee ${ }^{2 *}$ \\ ${ }^{1}$ Associate Professor, College of Nursing, Kyungbok University, Namyangju-si, Korea \\ ${ }^{2 *}$ Assistant Professor, Dept. of Nursing, Kyungnam University, Changwon-si, Korea \\ lyspark@kbu.ac.kr, ${ }^{2 *}$ Jeeyoungju@kyungnam.ac.kr
}

\begin{abstract}
The club activities allow students to have various experiences that is not addressed in the regular curriculum, and such activities related to their major affect their learning of major and college life. The purpose of this study was, for their effective club activities, to investigate the effect of club activities related to dementia on the students. The subjects were 26 students who participated in club activities for at least three hours per a week. The pre-and post-test measured their college life satisfaction, dementia knowledge, and dementia attitude and data were analyzed using descriptive statistics and paired sample t-test. The results showed that the scores of college life satisfaction, dementia knowledge, and dementia attitude increased significantly after club activities, indicating that the club activities related to dementia are effective in improving college life satisfaction, dementia knowledge, and dementia attitude. The results, however, should be confirmed in the replicate design study using control group sample.
\end{abstract}

Keywords: Dementia, Club activity, College life satisfaction, Dementia knowledge, Dementia attitude

\section{Introduction}

The college period, as an early stage of adulthood, is important in terms of personal growth and development and expected to explore important values in life, establish one's own identity, and appropriately cope with physical, social and psychological changes [1].

The college students lived a uniform and passive life, mainly for college entrance exams, until high school, however they are now expected to live autonomous and proactive life different from that of past, such as determining the courses by themselves, taking part in club activities while managing time, and preparing for careers and employment [2]. Some college students fail in adjusting to college and give up their studies due to the stresses resulting from the fact that it is a transitional period in which they have to focus on several tasks for transition to adulthood [3]. In addition, they experience negative and counterproductive emotions in various aspects such as anxiety, disappointment, regret, dissatisfaction, and hostility, instead of the joy, satisfaction, hope, and confidence of college life [2].

Article history:

Received (June 12, 2020), Review Result (July 14, 2020), Accepted (August 17, 2020) 
It is assumed that the college students who had healthier college life are more likely to have a positive adaptation life in adulthood [4]. The college life satisfaction, a predictor of high adaptability in social life after graduation, represents a positive experience, high achievement, and intrinsic motivation in the transition to adulthood, which leads to a feeling of satisfaction in everyday life [5].

The Club activity supports balanced development of mind and body and allows students to be free from environmental and situational stress [6], and is an important basis for university culture formation. The college students, by actively participating in various activities other than the curriculum in their leisure time, develop hobbies and talents, and have various experiences and wide range of encounters with students from other majors [7]. Since the club activity is done not only within the university but also outside the university, the spatial scope of the activities is also expanded. In addition, the club activity may enhance the social ability to fulfill responsibilities and obligations in an autonomous relationship [8] and complement the formal curriculum by expanding the aspects of affection and social experience that are not covered in the regular curriculum, which are helpful in achieving the purpose of university education, cultivating humans with holistic grounding [9]. Many researchers agreed on the necessity of activities to increase college life satisfaction, accordingly, investigated the effects of leisure activities [10], sports club activities [11], and music club activities [9]. Therefore, it is necessary to develop and apply various activities that can continuously provide opportunities for more activities to satisfy university life.

It is estimated that the number of patients with dementia among the elderly population aged 65 and over increase from about 540,000 in 2012 to about 1.27 million in 2030 and about 2.71 million in 2050, showing almost twice every 20 years [12]. Since the college students are not only the main actors in the support of the elderly in the future, but also have a direct relationship with the aging society [13] and the values and attitudes formed during college become a cornerstone for later life [14], the perception of college students about dementia is very important. It is important for the nursing students to have knowledge of dementia so that they provide more excellent care to the elderly with dementia.

Recently, the employment rate or grades are considered more frequently than one's aptitude and interest, in deciding major [15][16]. However, students who choose their major based on these criteria are I risk of experiencing low major satisfaction, which may have a negative impact on future careers [17]. Motivated by high employment rate, many students admitted to nursing department without much concern about the major. However, unlike other departments, nursing students, even when they are lower grade, take basic major courses such as anatomy, physiology, basic nursing, and practice, which require understanding and memorization of unfamiliar terms, which making them to complain of difficulties in university life adaptation and dissatisfaction with their major [15]. Shin et al. showed that volunteer activity related to major affects satisfaction with major [18], and these activities were reported to be effective in improving emotional intelligence and satisfaction with major [19]. Also, previous studies on dementia major learning in the field of nursing education showed that dementia partner education has a positive effect on dementia knowledge and attitude [20] and that volunteer activities for the elderly have an effect on knowledge and attitudes toward the elderly [21]. However, such studies especially those evaluating the effects of dementia club activities have been limited.

In particular, given that the problems of dementia elderly and their families are emerging as a social, national, and political issue due to the increase in the number of dementia elderly in Korea, and the elderly and dementia nursing is not considered an important subject because it is not included in the national nurse examination, it is important to provide club activities as 
an extra-curricular education method for the management of the dementia elderly. Therefore, it is very insightful to examine the effects of the dementia major club activities.

The purpose of this study was, therefore, to investigate the effect of dementia club activities on college life satisfaction, dementia knowledge, and dementia attitude and the specific ones are as follows:

(1) To measure the college life satisfaction after participating in dementia club activity.

(2) To measure the dementia knowledge and attitude after participating in dementia club activity.

\section{Method}

\subsection{Design \& subjects}

The purpose of this one group pretest-posttest study was to investigate the effect of volunteer activities for elderlies with dementia. The population was 44 nursing students participated in club activities for at least three hours per a week. The required number of subjects was calculated using $G^{*}$ Power 3.1 program following the principle of sample calculation based on Cohen formula [22], and determined as 27 with group number of 1, statistical power of 0.7, significance level of $\alpha=0.05$, and effect size of 0.5 for the paired sample t-test. After excluding participants who complete questionnaire unsatisfactory or stopped club activity, a total of 26 students were included as subjects.

\subsection{Measures}

\subsubsection{College life satisfaction}

The college life satisfaction was measured using the School Life Satisfaction Scale developed by Kim [23] that is self-administered one composed of six factors and 25 items of three items for overall satisfaction with school life, for items for interpersonal satisfaction, four items for lecture and learning satisfaction, four items for educational environment satisfaction, four items for school rule and special activity satisfaction, and six items for social support satisfaction. Each item was answered on five-point likert scale from 1 (definitely false) to 5 (definitely true). The Chronbach's $\alpha$ of this scale in this study was .76.

\subsubsection{Dementia knowledge}

The dementia knowledge was measured using questionnaire for awareness of dementia used in dementia prevalence survey in 2008 and 2012 [12], that is composed of 15 items of five items for etiology of dementia, three items for epidemiology and institution, four items for symptom and diagnosis, and three items for prevalence and treatment. Each item was answered on two-point likert scale of 1 (yes) and 2 (no).

\subsubsection{Dementia attitude}

The dementia attitude was measured using Dementia Attitudes Scale (DAS) developed by O'connor \& McFadden and composed of 20 items addressing dementia knowledge and social comfort [24]. Each question defines 'definitely false' as 1 point, and 'definitely true' as 7 points so the total score is 140 points. Six items were reverse coded, meaning that higher score represents more positive attitude toward dementia. 


\subsubsection{Degree of club activity}

The assessment for the quality of club activity used 'The criterion for the degree of club activity' developed by Jiyeon Kim [25]. It is design for the respondent to answer as one feels, and it consists 5 subordinate factors that assess the degree of the club activity. There are 20 questions in total. Each 3 questions for spontaneity, initiative, and problem solving, 7 questions for satisfactoriness, and 4 questions for organizational power. Each question is consisted of five-point likert scale and five points for 'definitely yes' and 1 point for 'definitely no', successively. In the survey by Kim [25] the Cronbach's a was .93.

\subsection{Club activity program operation}

The dementia club activities in this study are to provide cognitive rehabilitation programs for elderly with dementia living in homes or facilities. Prior to implementing program activities, meetings were held to plan programs, secure preparations, and acquire collaboration with responsible agencies. The cognitive rehabilitation program was provided for 50 minutes per a session.

\section{Data collection and analysis}

\subsection{Data collection and ethical consideration}

The data were collected from the students of a club in K University located in Gyeonggido who participated in club activities including meeting for over three hours per a week from Mar. 1 to Dec. 30, 2019. Data from 26 students were used in analysis after excluding 18 ones who have not completed questionnaire or stop club activity from qualified 44 ones. The questionnaire surveys were performed before and after club activity, respectively.

This study selected a club in K University and requested for research cooperation. After obtaining consent for research cooperation, the purpose of the study was explained to all subjects and written consents were obtained for each subject.

\subsection{Data analysis}

The methods for analyzing data are as follows:

(1) The general characteristics and motivation for joining club were analyzed using descriptive statistics (real number, percentage, and standard deviation)

(2) The effect of club activities on college life satisfaction, dementia knowledge, and dementia attitude were tested using t-test for pre-post comparison.

\section{Results}

\subsection{General characteristics of subjects}

Female subjects $(n=21 ; 80.8 \%)$ were more than male ones $(n=5 ; 19 \%)$. For the age, 19-23 and 24-27 years old accounted for $80.8 \%(\mathrm{n}=21)$ and $19.2 \%(\mathrm{n}=5)$, respectively. The most frequent length of club activity was less than one year $(\mathrm{n}=17 ; 65.4 \%)$, and followed by $1-2$ year $(n=5 ; 19.2 \%), 2-3$ years $(n=2 ; 7.7 \%)$, and three years or more $(n=2 ; 7.7 \%)$. The mean score of motivation for joining was $87.04 \pm 16.18$ from 120 [Table 1]. 
Table 1. General characteristics of subjects $(\mathrm{N}=26)$

\begin{tabular}{|c|c|c|}
\hline Characteristics & Category & Frequency (\%) \& Mean \\
\hline \multirow{2}{*}{ Gender } & Male & $5(19.2)$ \\
\cline { 2 - 3 } & Female & $21(80.8)$ \\
\hline \multirow{2}{*}{ Age } & $19-23$ years old & $21(80.8)$ \\
\cline { 2 - 3 } & $24-27$ years old & $5(19.2)$ \\
\hline \multirow{3}{*}{\begin{tabular}{c} 
Length of Club Activity \\
\cline { 2 - 3 }
\end{tabular}} & Less than one year & $17(65.4)$ \\
\cline { 2 - 3 } & More than one year & $5(19.2)$ \\
\cline { 2 - 3 } & More than two years & $2(7.7)$ \\
\hline $\begin{array}{c}\text { Mean Score of Motivation for } \\
\text { Joining (total 120) }\end{array}$ & More than three years & $2(7.7)$ \\
\hline
\end{tabular}

\subsection{Testing effect of club activity}

The results of testing the effect of club activity by comparing the score before and after activities showed that dementia knowledge $(\mathrm{t}=-5.56, \mathrm{p}<.001)$ and dementia attitude $(\mathrm{t}=-4.20$, $\mathrm{p}<.001)$ improved significantly after club activities. The score for college life satisfaction also improved though it did not reach statistical significance (pre-test: $91.38 \pm 9.63$, post=test: 94.08 \pm 15.60 ) [Table 2].

Table 2. The effects of club activity $(\mathrm{N}=26)$

\begin{tabular}{|c|c|c|c|c|}
\hline Parameter & $\begin{array}{c}\text { Pretest } \\
(\mathrm{M} \pm \mathrm{SD})\end{array}$ & $\begin{array}{c}\text { Posttest } \\
(\mathrm{M} \pm \mathrm{SD})\end{array}$ & $\mathrm{t}$ \\
\hline Degree of club activity & $91.38 \pm 9.63$ & $94.08 \pm 15.60$ & -.992 & .330 \\
\hline College Life Satisfaction & $98.54 \pm 11.71$ & $106.88 \pm 15.43$ & -2.38 & .025 \\
\hline Dementia Knowledge & $17.62 \pm 1.55$ & $22.62 \pm 4.02$ & -5.56 & $<.001$ \\
\hline Dementia Attitude & $108.88 \pm 14.02$ & $123.23 \pm 16.82$ & -4.20 & $<.001$ \\
\hline
\end{tabular}

\section{Conclusion}

This study investigated the effect of club activities for the elderlies with dementia on college life satisfaction, dementia knowledge, and dementia attitude in college students. This club activity is significant in that it is an extra-curricular activity that improves college life satisfaction, which can help with college life, and provides opportunity to learn knowledge and attitudes about dementia, a current national and social issue.

College students' club activities have been shown to be effective activities to induce efficient university life [10][11] and these results, as evidenced in Kim \& Han's study, which confirmed the positive effect of university student's leisure activities in school clubs on their companionship, organizational identity, and life satisfaction, suggest that the sense of belonging and the dynamic relationship between seniors and juniors within the club are 
effective activities for college life satisfaction. In addition, the results are similar to the report that the satisfaction level was high because they were able to get along with friends and become friends when they were active in sports clubs [26] and the research that college students' club activities had a direct effect on adapting to college life [27].

The results of this study showed that club activities significantly improved dementia knowledge and dementia attitude, consistent with the results that club activity is effective in improving college students' knowledge and attitude related to their major [9][18][20]. This result, given a study showing that volunteer activities of nursing college students have a significant effect on their satisfaction with major [19], is deemed to be from experiencing the process of raising interest in the major in club activities and meeting and caring for the patients with dementia. Based on the findings that the attitude toward dementia is positively correlated with the dementia education needs [28], the significantly improved attitude toward dementia in the dementia club activity provides evidence to improve the attitude toward dementia in college students.

One might be cautioned in generalizing the results of this study because this study targeted students from one university and one club, only the data from the subjects who participated in the study until the end were analyzed, and there was the possibility of spreading the subject's activities despite the researchers' preventive efforts.

This study may contribute to the field by providing fundamental data to be used developing and revising the club activities of college students.

\section{References}

[1] S. R. Noh and S. A. Bae, "The effects of emotional intelligence and learning flow on college adaptation in under graduate students," Journal of Learner-Centered Curriculum and Instruction, vol.14, no.2, pp.343-362, (2014)

[2] E. M. Park, "Effects of personality education program for university students," The Journal of the Korea Contents Association, vol.12, no.7, pp.497-509, (2012) DOI: 10.5392/JKCA.2012.12.07.497

[3] M. M. Chemers, M. Martin, L. T. Hu, and B.F. Garcia, "Academic self-efficacy and first year college student performance and adjustment," Journal of Educational Psychology, vol.93, no.1, pp.55-64, (2001) DOI: $10.1037 / \mathrm{h} 0053646$

[4] E. J. Park and H. K. Lee, "A study of factors affecting college dropout intention for freshmen in college: focused on k-college," Forum for youth culture, vol.41, pp.91-111, (2016)

[5] C. Levesque, A. N. Zuehlke, L. R. Stanek, and R. M. Ryan, "Autonomy and competence in german and american university students: a comparative study based on self-determination theory," Journal of Educational Psychology, vol.96, no.1, pp.68-84, (2004) DOI: 10.1037/h0053646

[6] S. U. Park, G. H. Hong, and H. H. Kang, "A study on the leisure satisfaction and collegiate-life satisfaction according to the types of circle activities," The Korean Journal of Physical Education, vol.41, no.5, pp.349356, (2004)

[7] D. J. Kim and Yang, "Relationships among activity types, activity satisfactions, activity constraints and university life satisfactions of university students" Circles, The Korean Journal of Physical Education, vol.7, no.4, pp.135-150, (2003)

[8] G. K. Kim, M. S. Kim, and B. J. Kim, " The effect of participation level in university club leisure activities on fun, commitment and psychological well-being," Korean Journal of Dance, vol.32, no.2, pp.33-46, (2015) DOI 10.21539/ksds.2015.32.2.33

[9] O. J. Lee and J. Y. Yoon, "The effects of music club experience on pre-teachers' pedagogical content knowledge in early childhood music", Korean Journal of Early Childhood Education and Care, vol.10, pp.4563, (2017) 
[10] Y. M. Kim and H. W. Han, "Influence of club leisure activity on peer relationship, organizational identification and life satisfaction of university students," Journal of Leisure, Recreation Studies, vol.34, no.2, pp.35-46, (2010)

[11] I. H. Kim, and C. H. Kim, "Influence of participation level in sport club activities on character competency and college adjustment in college students," The Korean Journal of Growth and Development, vol.26, no.4, pp.519-528, (2018)

[12] Ministry of Health and Welfare, 2012 national epidemiology survey of dementia, (2012)

[13] H. J. Lee, "Caregiving experience and adaptation process of the husbands who are caring for wives with Alzheimer-focusing on elderly couple household," Journal of the Korean Gerontological Society, vol.26, no.1, pp.45-62, (2006) DOI:10.31888/JKGS.2020.40.4.577

[14] M. S. Lee and S. N. Yang, "Effect of social work student's attitude, knowledge and experience with senior citizens," Journal of Digital Convergence, vol.10, no.8, pp.265-273, (2012) DOI:10.14400/JDPM.2012.10.8.265

[15] M. H. Nam and H O. Kim, "Relations between clinical practice emotional labor, Self- esteem and Major Satisfaction of among Nursing Students" Journal of Digital Convergence, vol.14, no.1, pp.263-273, (2016) DOI: $10.14400 / J D C$

[16] J. H. OH, "The Influencing factors of Self-esteem and Major Satisfaction on College Adjustment among Nursing Students, The Journal of the Korea Contents Association, vol.14, no.10, pp.873-884, (2014) DOI: 10.5392/JKCA.2012.12.07.497

[17] T. J. Jang, "The effect of nursing professionalism, satisfaction in major, and self-leadership on career preparation behavior in nursing students," M. S. thesis, Nursing Department, Keimyung University, Daegu, Korea, (2014)

[18] M. A. Shin and K. S. Ahn, "A study on satisfaction in major and job esteem based on volunteering experience of college students in the department of dental hygiene and nursing," Journal of Korean Society of Dental Hygiene, vol.12. no.6, pp.1090-1100, (2012)

[19] P. N. Park, "Relationships among volunteer activities, emotional intelligence and major satisfaction of nursing students," The Journal of the Korea Contents Association, vol.17, no.11, pp.264-273, (2017) DOI: 10.5392/JKCA.2012.12.07.497

[20] S. H. Jo and E. H. Kim, "A convergence study on the knowledge and attitudes of dementia parner nursing students on dementia," Journal of the Korea Convergence Society, vol.9, no.7, pp.317-323, (2018) DOI: 10. 15207/JKCS2018.9.7.317

[21] E. S. Cho, J. G. Moon, H. Y, Lee, and D. W. Han, "The effects of the participation in the voluntary service for the elderly on the cognition about the elderly of physical therapy students," Journal of the Korean Data Analysis Society, vol.14, no.3B, pp.1467-1477d (2012) DOI:10.37727/jkdas.2020.22.3.1265

[22] F. Faul, E. Erdfelder, A. Buchner, and A. G. Lang, "Statistical power analyses using G*Power 3.1: Tests for correlation and regression analyses," Behavior Research Methods, vol.41, pp.1149-1160, (2009) DOI: 10.3758/s13428-017-0890-x

[23] J. Y. Kim, "A study on the development and validation of the school life satisfaction scale for high school students,” M. S. thesis, Department of Education, Wonkwang University, Icsan, Korea, (2009)

[24] Melissa L. O'Connor and S. H. McFadden, "Development and psychometric validation of the dementia attitudes scale," International Journal of Alzheimer's Disease, vol.22, pp.1-10, (2010) DOI:10.4061/2010/454218

[25] J. Y. Kim, "A study on effect of club activity on affective behavioral characteristics in adolescents," M. S. thesis, Department of Education, Sookmyung University, Seoul, Korea, (2000)

[26] H. Yoo, "Sports club participation, college life satisfaction and sports club enjoyment", Asia-pacific Journal of Multimedia Services Convergent with Art, Humanities, and Sociology, vol.8, no.1 pp.245-252, (2018) DOI:10.35873/ajmahs.2018.8.1.025 
A Study on Effect of Club Activity for Elderly with Dementia on College Life Satisfaction, Dementia Knowledge, and Dementia Attitude

[27] S. M. Ham, "The Effects of Club Activities to College Life Adaptation: Based on the Mediator of Social Support and Grit”, Journal of Learner-Centered Curriculum and Instruction, vol.20, no.12 pp.327-348, (2020) DOI:10.22251/jlcci2020.20.12.327

[28] H. H. Eun, Factors Influencing Educational Needs for Dementia in Nursing students, Journal of the Korea Academia-Industrial, vol.19, no.3 pp.353-363, (2018) DOI:10.5762/KAIS.2018.19.3.353 